\title{
Melittin inhibits the invasion of MCF-7 cells by downregulating CD147 and MMP-9 expression
}

\author{
JIANJUN WANG, FENGYU LI, JIANG TAN, XUEWEI PENG, LILI SUN, PING WANG, \\ SHENGNAN JIA, QINGMIAO YU, HONGLIANG HUO and HONGYAN ZHAO \\ Laboratory of Molecular and Cellular Physiology, School of Life Science, Northeast Normal University, \\ Changchun, Jilin 130024, P.R. China
}

Received April 27, 2015; Accepted September 14, 2016

DOI: $10.3892 / \mathrm{ol} .2016 .5516$

\begin{abstract}
Tumor invasion and metastasis are the critical steps in determining the aggressive phenotype of human cancers. Melittin, a major component of bee venom, has been reported to induce apoptosis in several cancer cells. However, the mechanisms of melittin involvement in cancer invasion and metastasis remain unclear. Our previous study indicated that melittin inhibits cyclophilin A (CypA), a ubiquitously distributed peptidylprolyl cis-trans isomerase, in macrophage cells. In the present study, the Transwell assay results showed that melittin may downregulate the invasion level of MCF-7 cells in a dose-dependent manner. Additionally, it was also found, using flow cytometry and reverse transcription-polymerase chain reaction, that melittin decreased the expression of cluster of differentiation (CD)147 and matrix metallopeptidase-9 (MMP-9), whereas CypA upregulated the expression of CD147 and MMP-9. Overall, the present study indicated that melittin decreased the invasion level of MCF-7 cells by downregulating CD147 and MMP-9 by inhibiting CypA expression. The results of the present study provide an evidence for melittin in anticancer therapy and mechanisms.
\end{abstract}

\section{Introduction}

Invasion and metastasis is a complicated progress that is accomplished with the aid of numerous bioactive enzymes, such as plasmin, cathepsin and matrix metallopeptidases (MMPs) (1). MMPs are known to be $\mathrm{Zn}^{2+}$ dependent proteinases that have

Correspondence to: Mr. Hongliang Huo, Laboratory of Molecular and Cellular Physiology, School of Life Science, Northeast Normal University, 5268 Renmin Street, Changchun, Jilin 130024, P.R. China

E-mail: lify671@nenu.edu.cn

Abbreviations: MMP-9, matrix metallopeptidase 9; CD147, cluster of differentiation 147; CypA, cyclophilin A; RT-PCR, reverse transcription-polymerase chain reaction

Key words: melittin, CD147, cyclophilin A, MMP-9, MCF-7 cells also been reported to promote the invasion and metastasis of cancer cells by degradating the extracellular matix components to damage the histological barrier around the extracellular matrix (ECM) (2). MMP-9 is produced by mesenchymal, epithelial and hematopoietic cells, and also by distinct tumor cell types, such as those of gastric, lung and colon cancer. MMP-9 expression is induced by cytokines, growth factors and cell/stroma interactions, and has been associated with numerous biological processes, including bone resorption, inflammation and arthritis. Numerous studies have found that the invasion of breast cancer MCF-7 cells is hindered by the inhibition of MMP-9, which is expressed significantly more in carcinoma compared with normal tissues $(3,4)$. MMP-9 activity has also been linked with the process of tumor cell intravasation (5). These studies indicated that MMP-9 may be crucial in cancer invasion.

Melittin is a polypeptide containing 26 amino acid residues, which may inhibit the inflammatory stimulus of phospholipase A2 activity, and repress interleukin (IL)-1, tumor necrosis factor (TNF)- $\alpha$, cyclooxygenase, and reactive oxygen species in numerous inflammatory diseases, including rheumatoid arthritis in humans and experimental animals (6,7). Additionally, it has been reported that melittin could exert anti-cancer effects by suppressing the production of matrix metalloproteinase (MMPs), and inhibiting the activity of caspase (8-10). The caspase molecules are a class of highly-conserved protein molecules that are evolutionarily conserved and can be used in the detection of tumor cells (8-10).

CD147, a transmembrane glycoprotein, induces ECM metalloproteinase, which is widely expressed in numerous cells, particularly in malignant breast tumor, bladder tumor and catuneum carcinoma cells $(11,12)$. It has been known that CD147 promotes the expression of numerous members of the MMP family (12-15). Additionally, CD147 is also known as the receptor of cyclophilin A (CypA), which can induce numerous signal transductions and perform chemotactic activity (15). CypA is a cytosol protein in a number of cells that may be secreted in vesicles when stimulated by inflammatory factors or oxidative stress (16-19). Therefore, it is crucial to block carcinoma cell invasion through inhibiting CypA and CD147-induced MMP expression.

The previous study indicated that melittin may inhibit CypA expression in macrophage cells. The present study aims 
to investigate CypA-induced CD147 expression and MMP-9 secretion to identify notable targets of melittin involved in the invasion of mammary carcinoma MCF-7 cells. The invasion level of MCF-7 cells was found to be downregulated by melittin in a dose-dependent manner. And the results also showed that melittin could decrease the expression of CD147 and MMP-9, whereas CypA could upregulate the expression of CD147 and MMP-9 by using flow cytometry and reverse transcription-quantitative polymerase chain reaction (RT-qPCR). In summary, the present study demonstrated that melittin decreases the invasion level of MCF-7 cells by downregulating CD147 and MMP-9 through inhibition of CypA expression. The results of the present study provide evidence for melittin in anticancer therapy and mechanisms.

\section{Materials and methods}

Melittin and MCF-7 cell line. Synthetic high-purity melittin (Sigma-Aldrich; Merck Millipore, Darmstadt, Germany) was dissolved in sterile water, with the highest final concentration at $2.5 \mu \mathrm{g} / \mathrm{ml}(0,0.5,1.5$ and $2.5 \mu \mathrm{g} / \mathrm{ml})$ and stored at $-20^{\circ} \mathrm{C}$. The human breast carcinoma MCF-7 cell line (Beijing Dingguo Biological Technology Co., Ltd., Beijing, China) was cultured in Dulbecco's modified Eagle's medium (DMEM)-low glucose (Gibco; Thermo Fisher Scientific, Inc., Waltham, MA, USA), containing $10 \%$ fetal bovine serum (Beijing Sijiqing Buiological Science and Technology Co., Ltd., Beijing, China) and $1 \%$ antibiotics (penicillin and streptomycin; Beijing Dingguo Biological Technology Co., Ltd.), and subcultured at $37^{\circ} \mathrm{C}$ in a $5 \% \mathrm{CO}_{2}$ incubator.

Transwell assay. For the Transwell Matrigel invasion assay, $2 \times 10^{5}$ cells in $200 \mu \mathrm{l}$ of serum-free medium were plated onto the upper chamber of 24 -well Transwell inserts $(8-\mu \mathrm{m}$ pores; BD Biosciences, Franklin Lakes, NJ, USA) coated with or without Matrigel. Cells were incubated for $1 \mathrm{~h}$ for adherence and melittin was then added in the upper chamber for another $24 \mathrm{~h}$ at $37^{\circ} \mathrm{C}$ in a $5 \% \mathrm{CO}_{2}$ atmosphere. The lower chamber was filled with $600 \mu 1$ DMEM containing $10 \%$ fetal bovine serum. After $24 \mathrm{~h}$, the non-invaded cells were gently scraped off from the upper chamber by cotton swab. The cells were fixed with $10 \%$ methanol solution, which penetrated through the polyvinylidene difluoride membrane into the lower chamber, and then the cells were stained with $0.1 \%$ crystal violet (Beijing Dingguo Biological Technology Co., Ltd.) for $20 \mathrm{~min}$ at room temperature. Images of random fields were captured using a light inversion microscope system. The absorbance was determined using a microplate reader at a wavelength of $570 \mathrm{~nm}$ subsequent to destaining with $33 \%$ acetic acid.

ELISA. The expression of MMP-9 in MCF-7 was determined by ELISA using the human MMP-9 ELISA kit (Beijing Dingguo Biological Technology Co., Ltd.). The culture supernatants were harvested, centrifuged to remove cellular debris, and stored at $-80^{\circ} \mathrm{C}$ prior to ELISA. Each experiment was performed in triplicate and repeated three times. The MMP-9 concentration in the culture supernatant was quantified using ELISA kits (Beijing Dingguo Biological Technology Co., Ltd.), according to the manufacturer's instructions. The MMP-9 ELISA kit includes a set of calibration standards, which may produce a standard curve of optical density vs. MMP-9 concentration. The concentration of MMP-9 in the samples was determined by comparing the optical density (OD) of the samples at $450 \mathrm{~nm}$ to the standard curve.

$R T-q P C R$. Total RNA was extracted using TRIzol reagent (Takara Biotechnology Co., Ltd., Dalian, China). The quantity and purity of the isolated RNA were measured using OD at $260 \mathrm{~nm}$ and $280 \mathrm{~nm}$. Total RNA was reverse transcribed into cDNA, and then amplified by PCR using primer for CD147, MMP-9 according to the manufacturer's protocol (Takara Biotechnology Co., Ltd.). The primers used were as follows: CD147 forward, 5'-TCGCGCTGCTGGGCACC-3' and reverse, 5'-TGGCGCTGTCATTCAAGGA-3'; MMP-9 forward, 5'-CACTGTCCACCCCTCAGAGC-3' and reverse, 5'-GCCACTTGTCGGCGATAAGG-3'; and GADPH forward, 5'-TCGGAGTCAACGGATTTGGTCGTA-3' and reverse, 5'-TGGCATGGACTGTGGTCATGAGTC-3'. Cycling conditions were as follows: $64^{\circ} \mathrm{C}$ for $30 \mathrm{sec}$ for 35 cycles, $60^{\circ} \mathrm{C}$ for $30 \mathrm{sec}$ for 40 cycles and $64^{\circ} \mathrm{C}$ for $30 \mathrm{sec}$ for 30 cycles, respectively.

The primers were all purchased from Takara Biotechnology, Co., Ltd. The analysis of relative gene expression data was performed using RT-qPCR and the $2^{-\Delta \Delta C q}$ method (20). PCR products were then run on a $2 \%$ agarose gel in order to confirm the presence of a single band with the expected size using marker2000 (TianGen Biochemical Science and Technology, Co., Ltd. Beijing, China).

Flow cytometry analysis. MCF-7 cells were treated with trypsin, and then digestion was stopped using staining medium (phosphate-buffered saline containing 10\% serum protein was used after the filter). Centrifugation was performed at $4^{\circ} \mathrm{C}$ and $300 \times \mathrm{g}$ for $5 \mathrm{~min}$. Cells were incubated with phycoerythrin-labeled anti-CD147 monoclonal antibodies (1:100 dilution; ab91150; Abcam, Cambridge, UK) for $30 \mathrm{~min}$. The cells were mixed in ice-cold staining medium and centrifuged at $300 \mathrm{x} g$ for $5 \mathrm{~min}$ at $4^{\circ} \mathrm{C}$ three times. The cells were resuspended using staining medium and the supernatants were discarded. Positive cell count and mean fluorescence intensity were determined by flow cytometry.

Statistical analysis. All data were expressed as the mean \pm standard deviation. Statistical analyses were performed with Student's t-test using SigmaPlot 10.0 software (http://www.126xiazai.com/fileview_1619971.html). $\mathrm{P}<0.05$ was considered to indicate a statistically significant difference.

\section{Results}

Melittin inhibits MCF-7 cell invasion. Invasion is critical step in the initial progression of cancer and facilitates metastasis. Transwell assay was used to determine the effects of melittin on MCF-7 cell invasion. MCF-7 cells were treated with increasing doses of melittin $(0.5-2.5 \mu \mathrm{g} / \mathrm{ml})$, and invasion was assessed using the Transwell assay. It was found that treatment with melittin significantly decreased the invasion of MCF-7 cells in a dose-dependent manner $(\mathrm{P}=0.009, \mathrm{P}=0.007$ and $\mathrm{P}=0.006$, respectively) (Fig. $1 \mathrm{~A}$ and $\mathrm{B}$ ). 

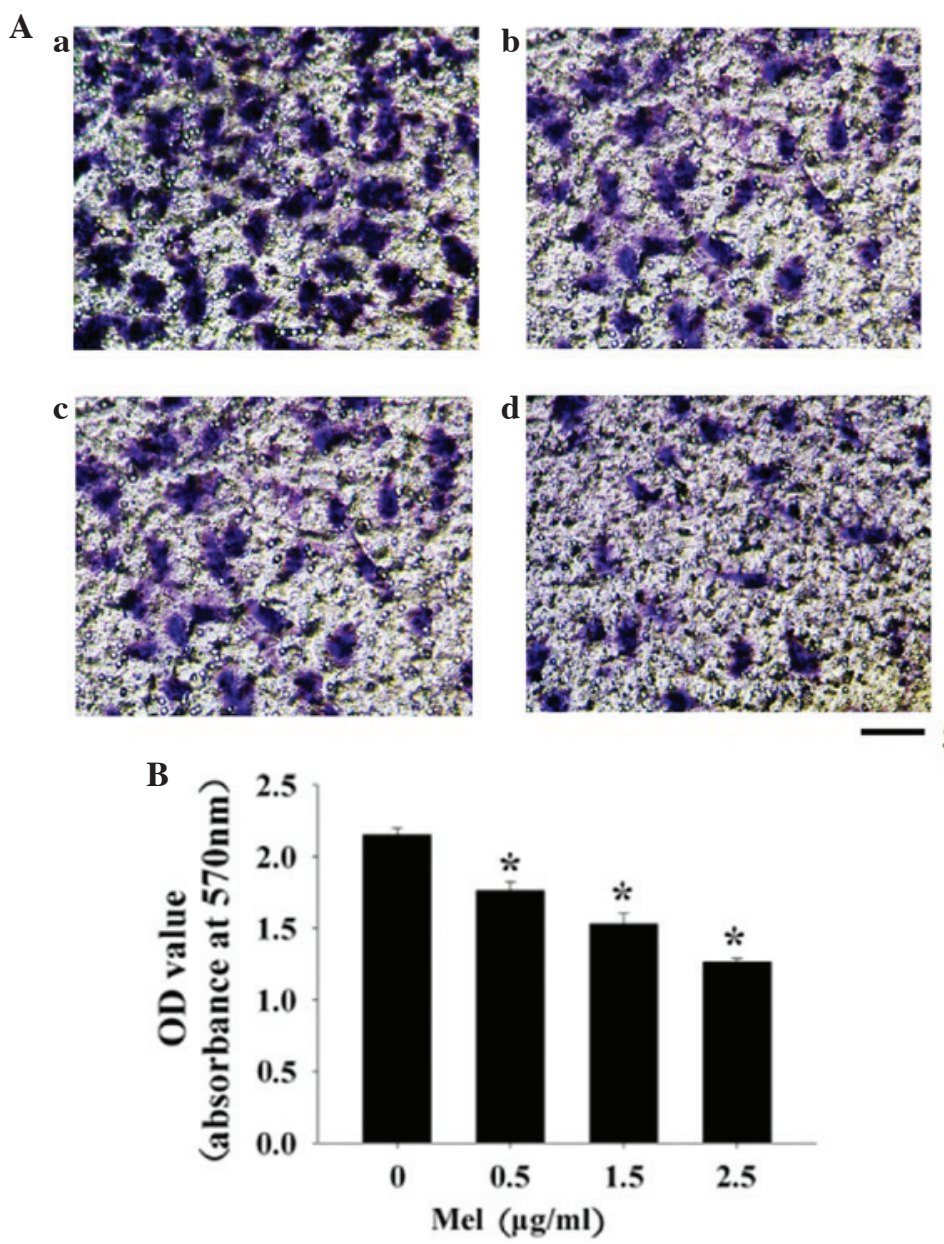

$50 \mu \mathrm{m}$ Figure 1. Melittin inhibits MCF-7 cell invasion. MCF-7 cells were plated onto the upper chamber. The cells were incubated for $1 \mathrm{~h}$ for adherence and then
treated with either Dulbecco's modified Eagle's medium (basal) or varying concentrations of melittin $(0.5-2.5 \mu \mathrm{g} / \mathrm{ml})$ in the upper chamber for $24 \mathrm{~h}$. The invasion was measured by Transwell assay. Scale bar, $50 \mu \mathrm{m}$. (A) Images of cells were captured using an inverted microscope subsequent to staining by crystal violet: (a) 0 , (b) 0.5 , (c) 1.5 and (d) $2.5 \mu \mathrm{g} / \mathrm{ml}$. (B) The absorbance was determined using a microplate reader at $570 \mathrm{~nm}$, subsequent to destaining with $33 \%$ acetic acid ( $\mathrm{P}<0.01$ vs. $0 ; \mathrm{n}=5)$. OD, optical density.

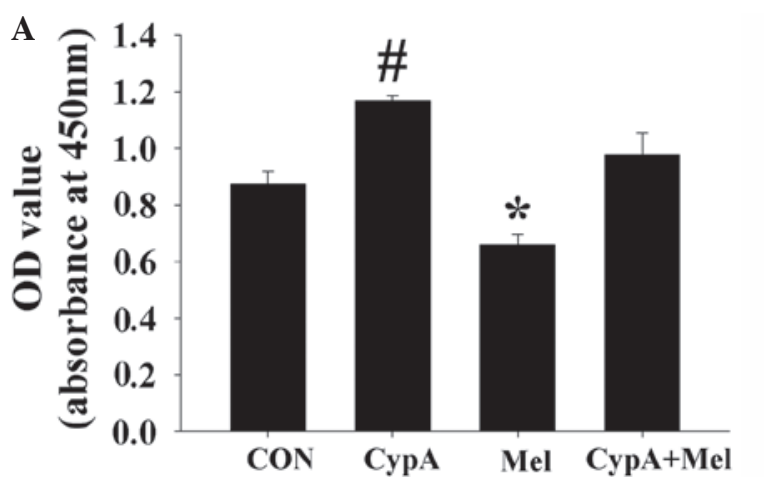

B

Figure 2. Melittin suppressed the expression and secretion of MMP-9 induced by CypA. MCF-7 cells were cultured in serum-free medium for $12 \mathrm{~h}$, and then the cells were incubated with $200 \mathrm{ng} / \mathrm{ml} \mathrm{CypA}$ and $2.5 \mu \mathrm{g} / \mathrm{ml}$ melittin for $24 \mathrm{~h}$. (A) The secretion of MMP-9 in MCF-7 was determined by ELISA using human MMP-9 ELISA kit. Following the calibration standards of the ELISA kit, the concentration of MMP-9 in the samples was determined by comparing the OD of the samples to the standard curve. (B) MMP-9 mRNA transcriptions was evaluated by reverse transcription-polymerase chain reaction. The expression of mRNA copies was normalized against GAPDH mRNA expression ( ${ }^{*} \mathrm{P}<0.05$ vs. CON, $\mathrm{n}=5$; ${ }^{*} \mathrm{P}<0.05$ vs. CypA, $\mathrm{n}=5$ ). MMP-9, matrix metallopeptidase 9; CypA, cyclophilin A; CON, control; Mel, metlittin; OD, optical density.

Melittin suppresses CypA-induced MMP-9 secretion. It has been reported that inhibition of MMP-9, which is significantly stimulated by CypA, hinders MCF-7 invasion. To evaluate whether MMP-9 stimulated by CypA may be repressed by melittin, ELISA and RT-PCR were performed to detect the expression of MMP-9 in MCF-7. ELISA and RT-PCR results showed that extracellular CypA increased MMP-9 expression and secretion, while melittin suppressed MMP-9 
A

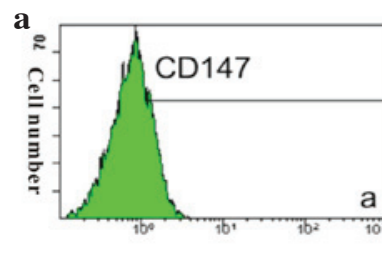

b

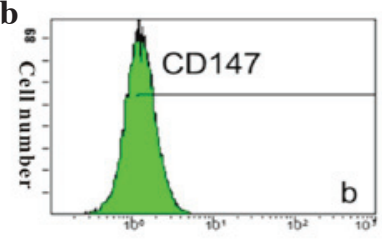

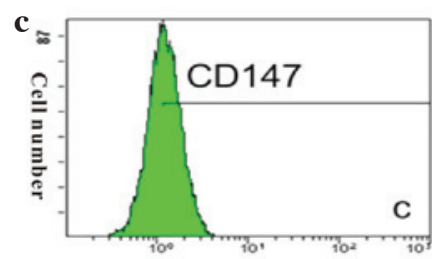
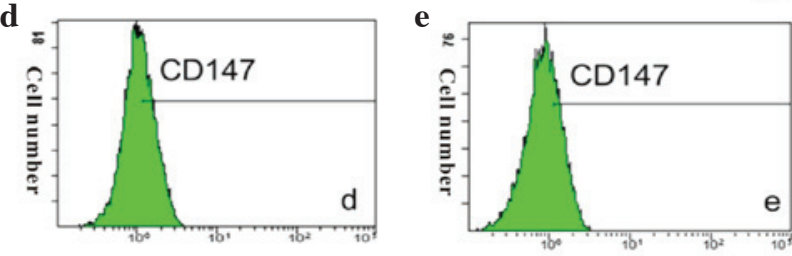

f
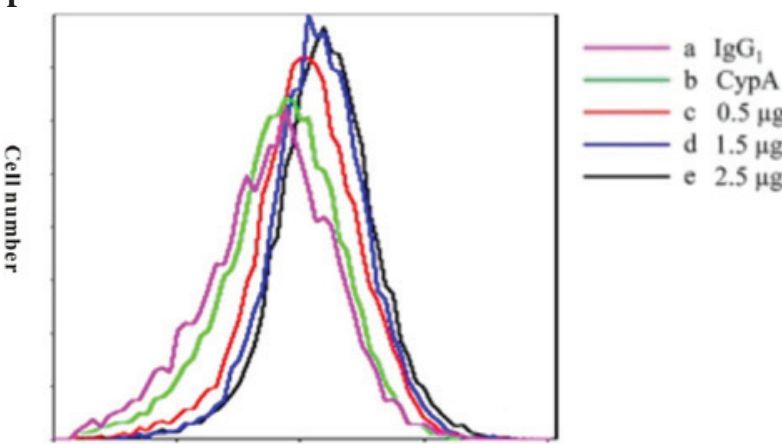

c $0.5 \mu \mathrm{g} / \mathrm{ml}$ melittin

d $1.5 \mu \mathrm{g} / \mathrm{ml}$ melittin

- e $2.5 \mu \mathrm{g} / \mathrm{ml}$ melittin

B

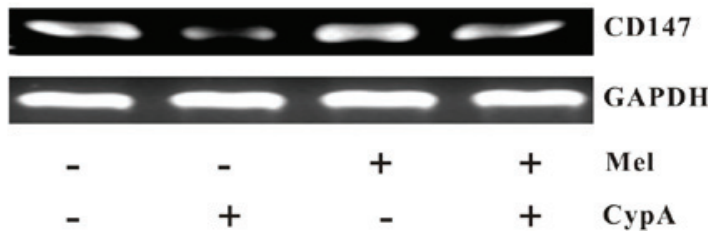

Figure 3. Melittin antagonizes CD147 expression stimulated by CypA. (A) CD147 expression in MCF-7 cells was detected by flow cytometry. MCF-7 cells were incubated with phycoerythrin-labeled anti-CD147 monoclonal antibodies (cells incubated with $\operatorname{IgG}_{1}$ were used as the control group). (A-a) $\operatorname{Ig} \mathrm{G}_{1}-\mathrm{labeled}$ group; (A-b) CypA-stimulated group; (A-c) $0.5 \mu \mathrm{g} / \mathrm{ml}$ melittin; (A-d) $1.5 \mu \mathrm{g} / \mathrm{ml}$ melittin; (A-e) $2.5 \mu \mathrm{g} / \mathrm{ml}$ melittin; (A-f) summary of the results of the aforementioned 5 groups. (B) CD147 mRNA transcription in MCF-7 cells was detected by reverse transcription-polymerase chain reaction. MCF-7 cells incubated with $200 \mathrm{ng} / \mathrm{ml} \mathrm{CypA}$ and $2.5 \mu \mathrm{g} / \mathrm{ml}$ melittin for $24 \mathrm{~h}$ following culture in serum-free medium for $12 \mathrm{~h}$. The expression of mRNA copies was normalized against GAPDH mRNA expression (2). CD147, cluster of differentiation 147; $\mathrm{IgG}_{1}$, immunoglobulin G1; CypA, cyclophilin A; Mel, melittin.

expression and secretion induced by CypA $(\mathrm{P}=0.042$ and $\mathrm{P}=0.039$ ) (Fig. 2A and B). The present results indicate that melittin could decrease MMP-9 expression and secretion, which may be associated with extracellular CypA.

Melittin suppressed CypA-stimulated CD147 expression. It is well known that CD147, a matrix metalloproteinase inducer factor, promotes MMP family expression (12-15). Additionally, it has also been reported that CD147 contributes to the signal transduction pathway induced by CypA (21). In the present study, in order to investigate whether melittin antagonizes CD147 expression that is induced by CypA, flow cytometry and RT-PCR were performed to assess the expression of CD147 in MCF-7 cells. The flow cytometry assay showed that CypA can stimulate CD147 expression, while melittin decreases the expression of CD147 in a dose-dependent manner at concentrations between 0.5 and $2.5 \mu \mathrm{g} / \mathrm{ml}$ (Fig. 3A). In addition, the RT-PCR results also indicated that CD147 mRNA expression stimulated by CypA was antagonized by melittin at a concentration of $2.5 \mu \mathrm{g} / \mathrm{ml}$ (Fig. 3B).

\section{Discussion}

At present, several studies have reported that the antineoplastic effect of melittin is involved in liver, lung, prostate and breast cancers, and other malignant tumors (22). Park et al found that melittin suppressed breast cancer cell invasion and tumor growth (23). Additionally, in the present study, it was found that melittin inhibited breast cancer MCF-7 cell invasion in a dose-dependent manner.

MMPs are a family of secreted or transmembrane enzymes that can collectively digest almost all ECM and basement membrane components. Thus, MMPs are largely implicated in promoting angiogenesis and tumor metastasis $(24,25)$. Numerous studies have found that the breast cancer MCF-7 cell invasion can be hindered by the inhibition of MMP-9, which is overexpressed in carcinoma compared with normal tissue $(9,10)$. MMP-9 activity has also been linked with the process of tumor cell intravasation. These studies indicated that MMP-9 may play a crucial role in cancer invasion. In dendritic cells, increased expression of cell migration was shown to be significantly enhanced (26). Therefore, regulation 
of MMP-9 expression and secretion has become an important focus of studies investigating anticancer drugs. The present study indicates that melittin inhibits MCF-7 invasion by repressing MMP-9 expression. Additionally, Cho et al have confirmed the effect of melittin on MMP-9 expression induced by phorbol-12-myristate-13-acetate (PMA) (3). Although melittin has been reported to inhibit the invasion of breast cancer cells, the effect of melittin on normal cells is not clear.

CD147, namely matrix metalloproteinase induced factor, can promote the expression and secretion of MMPs, and widely expressed in numerous types of cells, particularly malignant tumors, including mammary carcinoma and bladder cancer (27). Seizer et al (28) found that CD147 was upregulated during the differentiation process between CD34(+) progenitor cells and foam cells, and the CypA/CD147 activation pathway may be involved in promoting the vulnerability of atherosclerotic plaques. In addition, Gou et al reported that high expression of CD147, MMP-2 and MMP-9 were associated with laryngeal carcinoma invasion and metastasis (24). Additionally, previous studies have identified that CD147 inhibition and subsequent MMP-9 deletion may have anti-tumor effects by inhibiting the invasiveness of human cervical squamous carcinoma cells (29-31). The aforementioned studies indicated that high expression of CD147 may be another crucial factor in the invasion and metastasis of malignant tumor cells. In the present study, it was found that CD147 mRNA expression stimulated by CypA was antagonized by melittin, which indicated that melittin inhibited MCF-7 invasion through antagonizing CD147 mRNA expression stimulated by CypA.

In the present study, CypA stimulated MCF-7 cell invasion by inducing CD147 expression and MMP-9 secretion, whereas the invasion of MCF-7 cells was inhibited by melittin. Our previous study demonstrated that melittin suppresses CypA secretion in mouse macrophage Raw264.7 cells (31). Thus, it has been indicated that melittin decreases the invasion of MCF-7 cells in numerous ways. CypA is a widely expressed cytosol protein that can be secreted to extracellular space as a cytokine when stimulated by inflammatory factors or oxidative stress (32-34). CypA can not only increase the expression of CD147 and the expression of downstream factors, but also take part in the feedback regulation of CD147 (18). Thus, there is a potential pathway that melittin may suppress CypA secretion through inhibiting CD147 and MMP-9. This remains to be further studied in depth.

In summary, the present study indicated that melittin inhibits breast carcinoma MCF-7 cell invasion by interacting with numerous targets and provided experimented basis for melittin used for anti-cancer treatment.

\section{Acknowledgements}

This study was supported by Natural Science Fund of Jilin (grant no., 201215001) and The National Natural Science Foundation of China (grant no., 51478096).

\section{References}

1. Aimes RT and Quigley JP: Matrix metalloproteinase-2 is an interstitial collagenase. Inhibitor-free enzyme catalyzes the cleavage of collagen fibrils and soluble native type I collagen generating the specific 3/4- and 1/4-length fragments. J Biol Chem 270: 5872-5876, 1995.
2. Folgueras AR and Pendás AM, Sánchez LM and López-Otin C: Matrix metalloproteinases in cancer: From new functions to improved inhibition strategies. Int J Dev Biol 48: 411-424, 2004.

3. Cho HJ, Jeong YJ, Park KK, Park YY, Chung IK, Lee KG, Yeo JH, Han SM, Bae YS and Chang YC: Bee venom suppresses PMA-mediated MMP-9 gene activation via JNK/p38 and NF-kappaB-dependent mechanisms. J Ethnopharmacol 127: $662-668,2010$

4. Decock J, Hendrickx W, Vanleeuw U, Van Belle V, Van Huffel S, Christiaens MR, Ye S and Paridaens R: Plasma MMP1 and MMP8 expression in breast cancer: Protective role of MMP8 against lymph node metastasis. BMC Cancer 8: 77, 2008.

5. Ramos-DeSimone N, Hahn-Dantona E, Sipley J, Nagase H, French DL and Quigley JP: Activation of matrix metalloproteinase-9 (MMP-9) via a converging plasmin/stromelysin-1 cascade enhances tumor cell invasion. J Biol Chem 274: 13066-13076, 1999.

6. Cho HJ, Jeong YJ, Park KK, Park YY, Chung IK, Lee KG, Yeo JH, Han SM, Bae YS and Chang YC: Bee venom suppresses PMA-mediated MMP-9 gene activation via JNK/p38 and NF-kappaB-dependent mechanisms. J Ethnopharmacol 127): 662-668, 2009

7. Somerfield SD, Stach JL, Mraz C, Gervais F and Skamene E: Bee venom melittin blocks neutrophil $\mathrm{O}_{2}{ }^{-}$production. Inflammation 10: 175-182, 1986.

8. Russell PJ, Hewish D, Carter T, Sterling-Levis K, Ow K, Hattarki M, Doughty L, Guthrie R, Shapira D, Molloy PL, et al: Cytotoxic properties of immunoconjugates containing melittin-like peptide 101 against prostate cancer: In vitro and in vivo studies. Cancer Immunol Immunother 53: 411-421, 2004.

9. Li B, Gu W, Zhang C, Huang XQ, Han KQ and Ling CQ: Growth arrest and apoptosis of the human hepatocellular carcinoma cell line BEL-7402 induced by melittin. Onkologie 29: 367-371, 2006.

10. Hu H, Chen D, Li Y and Zhang X: Effect of polypeptides in bee venom on growth inhibition and apoptosis induction of the human hepatoma cell line SMMC-7721 in-vitro and Balb/c nude mice in-vivo. J Pharm Pharmacol 58: 83-89, 2006.

11. Bordador LC, Li X, Toole B, Chen B, Regezi J, Zardi L, Hu Y and Ramos DM: Expression of emmprin by oral squamous cell carcinoma. Int J Cancer 85: 347-352, 2000.

12. Taylor PM, Woodfield RJ, Hodgkin MN, Pettitt TR, Martin A, Kerr DJ and Wakelam MJ: Breast cancer cell-derived EMMPRIN stimulates fibroblast MMP2 release through a phospholipase A (2) and 5-lipoxygenase catalyzed pathway. Oncogene 21: 5765-5772, 2002.

13. Caudroy S, Polette M, Nawrocki-Raby B, Cao J, Toole BP, Zucker S and Birembaut P: EMMPRIN-mediated MMP regulation in tumor and endothelial cells. Clin Exp Metastasis 19: 697-702, 2002.

14. Biswas C: Collagenase stimulation in cocultures of human fibroblasts and human tumor cells. Cancer Lett 24: 201-207, 1984.

15. Gabison EE, Hoang-Xuan T, Mauviel A and Menashi S: EMMPRIN/CD147, an MMP modulator in cancer, development and tissue repair. Biochimie 87: 361-368, 2005.

16. Jin ZG, Melaragno MG, Liao DF, Yan C, Haendeler J, Suh YA, Lambeth JD and Berk BC: Cyclophilin A is a secreted growth factor induced by oxidative stress. Circ Res 87: 789-796, 2000.

17. Suzuki J, Jin ZG, Meoli DF, Matoba T and Berk BC: Cyclophilin $\mathrm{A}$ is secreted by a vesicular pathway in vascular smooth muscle cells. Circ Res 98: 811-817, 2006.

18. Nishioku T, Dohgu S, Koga M, Machida T, Watanabe T, Miura T, Tsumagari K, Terasawa M, Yamauchi A and Kataoka Y: Cyclophilin A secreted from fibroblast-like synoviocytes is involved in the induction of CD147 expression in macrophages of mice with collagen-induced arthritis. J Inflamm (Lond) 9: 44, 2012.

19. Pap T: Cyclophilins in rheumatoid arthritis-stepping into an undiscovered country? Clin Immunol 116: 199-201, 2005.

20. Livak and Schmittgen: Analysis of relative gene expression data using real-time quantitative PCR and the $2-\Delta \Delta \mathrm{Ct}$ method. Methods 25: 402-408, 2001.

21. Lai W C, Zhou M, Shankavaram U, Peng G and Wahl LM: Differential regulation of lipopolysaccharide-induced monocyte matrix metalloproteinase (MMP)-1 and MMP-9 by p38 and extracellular signal-regulated kinase $1 / 2$ mitogen-activated protein kinases. J Immunol 170: 6244-6249, 2003.

22. Jang MH, Shin MS, Lim S, Han SM, Park HJ, Shin I, Lee JS, Kim KA, Kim EH and Kim CJ: Bee venom induces apoptosis and inhibits expression of cyclooxygenase-2 mRNA in human lung cancer cell line NCI-H1299. J Pharmacol Sci 91: 95-104, 2003. 
23. Park JH, Jeong YJ, Park KK, Cho HJ, Chung IK, Min KS, Kim M, Lee KG, Yeo JH, Park KK and Chang YC: Melittin suppresses PMA-induced tumor cell invasion by inhibiting NF-kappaB and AP-1-dependent MMP-9 expression. Mol Cells 29: 209-215, 2010.

24. Gou X, Chen H, Jin F, Wu W, Li Y, Long J, Gong X, Luo M, $\mathrm{Bi}$ T, Li Z and He Q: Expressions of CD147, MMP-2 and MMP-9 in laryngeal carcinoma and its correlation with poor prognosis. Pathol Oncol Res 20: 475-481, 2014.

25. Cheung LW, Leung PC and Wong AS: Gonadotropin-releasing hormone promotes ovarian cancer cell invasiveness through c-jun NH2-terminal kinase-Mediated activation of matrix metalloproteinase (MMP)-2 and MMP-9. Cancer Res 66: 10902-10910, 2006.

26. Yen J H, Kocieda V P, Jing H and Ganea D: Prostaglandin E2 induces matrix metalloproteinase 9 expression in dendritic cells through two independent signaling pathways leading to activator protein 1 (AP-1) activation. J Biol Chem 286: 38913-38923, 2011.

27. Yurchenko V, Constant S, Eisenmesser E and Bukrinsky M: Cyclophilin-CD147 interactions: A new target for anti-inflammatory therapeutics. Clin Exp Immunol 160: 305-317, 2010.

28. Seizer P, Fuchs C, Ungern-Sternberg SN, Heinzmann D, Langer H, Gawaz M, May AE and Geisler T: Platelet-bound cyclophilin A in patients with stable coronary artery disease and acute myocardial infarction. Platelets 27: 155-158, 2016.
29. Farabegoli F,Papi A and Orlandi M:(-)-Epigallocatechin-3-gallate down-regulates EGFR, MMP-2, MMP-9 and EMMPRIN and inhibits the invasion of MCF-7 tamoxifen-resistant cells. Biosci Rep 31: 99-108, 2011.

30. Fan X, Wu W, Shi H and Han J: RNA interference targeting CD147 inhibits the invasion of human cervical squamous carcinoma cells by downregulating MMP-9. Cell Biol Int 37: 737-741, 2013.

31. Dang D, Atakilit A and Ramos DM: EMMPRIN modulates migration and deposition of TN-C in oral squamous carcinoma. Anticancer Res 28: 2049-2054, 2008.

32. Trachtenberg A, Pushkarsky T, Heine S, Constant S, Brichacek B and Bukrinsky M: The level of CD147 expression correlates with cyclophilin-induced signalling and chemotaxis. BMC Res Notes 4: 396, 2011.

33. Takahashi M, Suzuki S and Ishikawa K: Cyclophilin A-EMMPRIN interaction induces invasion of head and neck squamous cell carcinoma. Oncol Rep 27: 198-203, 2012.

34. Yang Y, Lu N, Zhou J, Chen ZN and Zhu P: Cyclophilin A up-regulates MMP-9 expression and adhesion of monocytes/macrophages via CD147 signalling pathway in rheumatoid arthritis. Rheumatology (Oxford) 47: 1299-1310, 2008. 